\title{
Current situation of action on mycotoxins and surveillance of mycotoxin contamination in Mongolia
}

\author{
Oyunchimeg Batkhuu ${ }^{\top}$, Sainjargal Dorjgotov ${ }^{1}$ \\ ${ }^{1}$ National Reference Laboratory for Food Safety (NRLFS), General Agency for Specialized Inspection, \\ Khan-Uul district, Chinggis avenue, $2^{\text {nd }}$ khoroo, Ulaanbaatar, Mongolia
}

\author{
Keywords \\ food; Mongolia; mycotoxin \\ contamination; NRLFS; risk \\ assessment

\section{Correspondence \\ Oyunchimeg Batkhuu, Khan-Uul district, Chinggis avenue, $2^{\text {nd }}$ khoroo, Ulaanbaatar, Mongolia E-mail: smileuka@yahoo.com; yuna2868@gmail.com}

\begin{abstract}
In Mongolia, systematic surveillance of mycotoxins has been conducted from 2009 by National Reference Laboratory for Food Safety. This manuscript reports the results briefly.
\end{abstract}

(Received November 26, 2016, accepted November 30, 2016)
A mycotoxin is a toxic secondary metabolite produced by fungi, also known as molds, and is usually produced by fungi belonging to the genera Aspergillus, Penicilium and Fusarium. Such mycotoxins contaminate food products and raw materials used for food production and animal feeds, and are highly dangerous to human health, including the risk of causing cancer, immune deficiency, and mutation.

Around $70 \%$ of Mongolia's food imports are from China, Russia and South Korea. Basic food commodities imported in 2009-2012 that might have the risk of containing mycotoxins are grains (4.1-114.7 thousand tons), flour (50.1-105.7 thousand tons), flour products (9.2-14.8 thousand tons), rice (12-31.6 thousand tons) and millet (1.3-1.9 thousand tons) ${ }^{1)}$.

In our country, incidences of liver cancer are becoming more common among younger people according to statistics covering the last 5 years, and causes identified by pathological_examination point to bad lifestyle, wrong eating habits, and low quality food.

Studies done by the National Cancer Center of Mongolia show that the incidence of cancer per 10,000 people in 2011 and 2012 was considerably higher compared to that in 2009 and 2010. The percentage of patients with liver cancer was $6.6 \%$, uterine cancer was $2.4 \%$, lung cancer was $1.2 \%$, esophageal cancer was $1 \%$, other diseases were $3.9 \%$, and other cancers were $4.2 \%$ per 10,000 people p. $^{2}$.

In the Mongolian food industry, imported food- stuffs such as nuts, corn, beans, soy, rice, dried fruits and breakfast cereals that may contain mycotoxin are sold widely; however, no investigations have been carried out to measure mycotoxin contamination in these products. Therefore, carrying out regular control studies of mycotoxin levels in imported food products is important for reducing health risks and diseases in the population of the country.

The National Reference Laboratory for Food Safety (NRLFS), General Agency for Specialized Inspection Mongolia, approved a national standardized screening method using ELISA for seven types of mycotoxins in imported and exported goods in 2007. The laboratory also set national standards for maximum permissible residue levels of mycotoxins contained in food products and animal feed, and has been ensuring regulatory compliance to these standards in Mongolia ${ }^{3)}$.

In 2015, the Center for Research and Risk Assessment; Chemical and Toxicological Laboratory and Microbiology Laboratory at NRLFS, together with the Ministry of Health, initiated the first study of risk assessment for mycotoxins in food products in Mongolia.

The aim of this research thesis was to define aflatoxin B1, B2, G1, G2, M1 and M2 in some food goods, the risk of toxicity from mycotoxin in some Mongolian phytogenic medicines, and from ochratoxin A in nonprocessed wheat and beer. The thesis also aimed to evaluate allowable amounts of mycotoxins and develop recommendations for decreasing the amounts of afla- 
toxin and ochratoxin in food and Mongolian phytogenic medicines. We used an ELISA method.

However, the results obtained from this study are not reliable as too few samples were used and the ELISA method used is not a confirmation method.

To summarize the results, the priority is to study international confirmation methods and utilize the most appropriate one in Mongolia. This will not only aid mycotoxin control research in food, wheat, and animal feed, but it will also decrease risks that can influence human health and disease.

Therefore, we will develop technical and human resources by cooperating with international organizations and introduce an appropriate mycotoxin analysis method in Mongolia.

\section{References}

1) Mongolian Custom House

2) National Statistics Office of Mongolia

3) Agency for Standardization and Metrology, 2009, Mongolian standard. Immunofermentation method /Eliza/ for defining aflatoxin B1 content MNS 6045:2009. 